\title{
Runway performance of normal and anosmic rats as a function of reward magnitude: A preliminary report*
}

\author{
BERNABE MARRERO and STEPHEN F. DAVIS \\ Austin Peay State University, Clarksville, Tenn. 37040
}

and

JOHN D. SEAGO

Concord College, Athens, W. Va. 24712

\begin{abstract}
Two groups of normal rat Ss received 50 acquisition trials with large and small reward magnitudes, respectively. Two groups of anosmic Ss were trained under the same conditions. The results indicated that reward magnitude was positively related to performance in all measures for the normal Ss, but not for the anosmic Ss. The results are seen as: (1) supporting the traditional assumption of the effectiveness of reward magnitude, and (2) cautioning against the use of anosmic Ss as an odor control procedure until the full behavioral effects of anosmia are delineated.
\end{abstract}

An assumption traditionally accepted by many researchers in the field of animal learning (see Pubols, 1960) concerns the role of reward magnitude. Typically it has been assumed that larger reward magnitudes resulted in faster acquisition and/or higher asymptotic performance levels. Recently, however, McCain (1969, $1970,1971)$ has questioned the validity of this assumption. The data reported by $\mathrm{McCain}$ indicated that reward magnitude effects did develop after limited training or during the early portions of extended training. However, these differences became smaller as the number of acquisition trials increased and were virtually nonexistent after approximately 50 trials.

However, the McCain $(1969,1970,1971)$ data have not gone unchallenged. For example, Traupmann \& Wong (1971) suggested that the receipt of $3,000 \mathrm{mg}$ (total) of reward during a 36-min experimental session may have satiated the Ss. Secondly, they criticized the measure, mean median running time, reported by McCain, and suggested that a speed measure (i.e., reciprocal transformation) might have yielded significant differences. Daly (1972), on the other hand, has recently presented data which conflict with those reported by McCain. Using the same reward magnitudes as used in the McCain studies, she reported that significant speed-measure differences did develop and, further, that these differences persisted throughout the course of a 60-trial acquisition phase.

The present study was designed with a twofold purpose in mind. First, it was designed to investigate possible reward magnitude effects in a situation where the reward magnitude for large-reward Ss and the

\footnotetext{
*Requests for reprints should be sent to Stephen F. Davis, Department of Psychology, Austin Peay State University, Clarksville, Tenn. 37040. This paper is sponsored by Robert $E$. Prytula, who takes full editorial responsibility for its contents.
}

number of trials per day were not as great as in the McCain $(1969,1970,1971)$ and Daly (1972) studies. Hopefully, this would eliminate the possible effects of satiation. Secondly, two groups of surgically anosmic Ss were to be run under large- and small-reward conditions, respectively. Recently, a sizable number of studies indicating that olfactory cues may play an influential role in animal maze learning have begun to appear in the literature. The reader may wish to consult Cheal \& Sprott (1971) for a review of this work. Several methods of odor control have been suggested to date; however, the ultimate odor control would appear to be the use of surgically anosmic Ss. At present the behavioral effects of rendering rat Ss anosmic are not well delineated. The present study was also designed to be a preliminary investigation into the behavioral effects produced by anosmia.

\section{METHOD \\ Subjects}

The Ss were 20 naive female albino rats obtained from Cherokee Labs, Atlanta, Georgia. Ten of the Ss were rendered anosmic in the following manner. First, the Ss were anesthesized with ether. Then, trephine openings, guided by a stereotaxic instrument, were placed on each side of the saggital suture above the olfactory bulb. The olfactory bulbs and connecting olfactory tracts were removed with an aspirator from each $S$. At the beginning of the experiment, the Ss were approximately 110 days old. They were housed in individual cages with water always available. Two weeks before the beginning of the experiment, the Ss were placed on food deprivation and were maintained at $85 \%$ ad lib body weight during the experiment. All Ss were fed following the completion of the daily experimental session.

\section{Apparatus}

The apparatus, more fully described in Davis (1973), consisted of a single straight runway. The runway was divided into a $38.10-\mathrm{cm}$ gray startbox, a $91.44-\mathrm{cm}$ black run section, and a $30.48-\mathrm{cm}$ black goalbox. Hardware cloth tops covered by a thin transparent sheet of plastic covered the entire apparatus. A microswitch located on the start door in conjunction with a series of photoelectric cells activated electric timers, thus yielding start, run, and goal times.

\section{Procedure}

Upon the inception of the deprivation schedule, the normal Ss were randomly assigned to two groups: LS-R and SS-R. Likewise, the anosmic Ss were randomly assigned to two groups: LS-A and SS-A. The 6 days immediately preceding the experiment constituted a pretraining phase for all Ss. During pretraining, all Ss were handled and tamed (Days 1-4), allowed to explore the apparatus (Days 5-6), and pellet habituated in the home cage (Days 1-6). A 50-trial acquisition phase (two trials per day) immediately followed pretraining. Groups LS-R and LS-A received large reward (one 300-mg Noyes pellet), while Groups SS-R and SS-A received small reward (one $45-\mathrm{mg}$ Noyes pellet).

Groups SS-A and LS-A and Groups SS-R and LS-R were run as two separate squads, with the squad composed of Groups SS-R and LS-R being run first on all days in an attempt to minimize the transmission of any odor cues from the anosmic to 


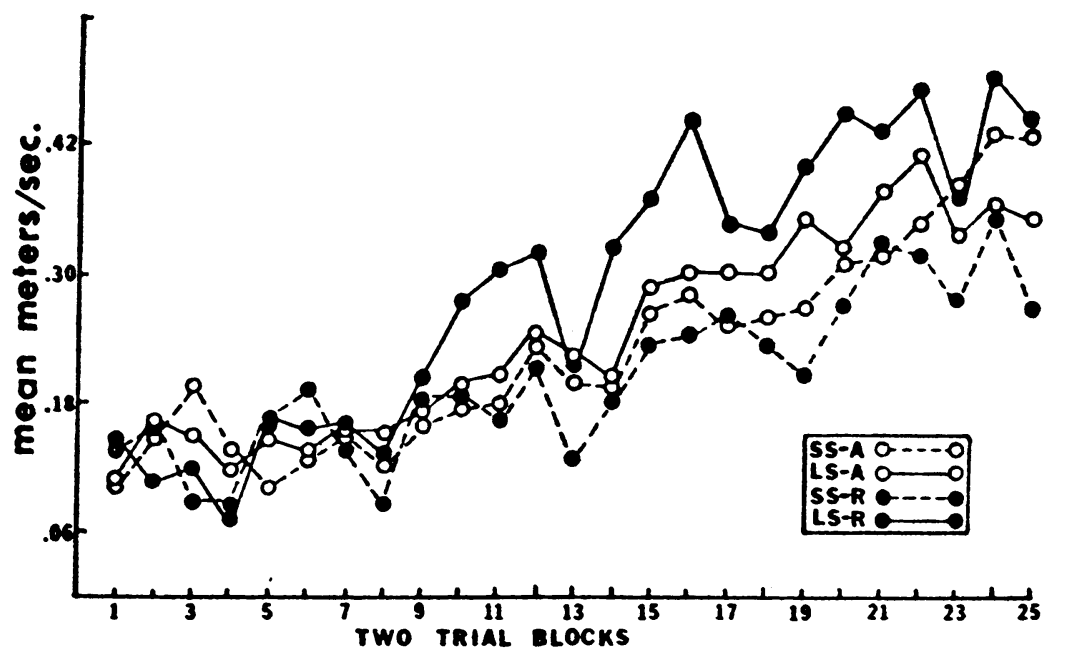

Fig. 1. Mean goal speeds (meters per second) during acquisition.

the normal Ss. The order of running Ss within each squad was randomized daily.

\section{RESULTS AND DISCUSSION}

In Fig. 1, mean goal speeds (meters per second) during acquisition are shown. Analysis of variance was performed on the speed data for all three measures for Trial Blocks 19-25 (the point in training at which asymptotic performance appeared to have been reached). The results of these analyses indicated that the Olfactory State by Reward Magnitude interactions were significant in all three measures (start, $F=14.09$, $\mathrm{df}=$ $1 / 19, \mathrm{p}<.01$; run, $\mathrm{F}=6.135$, df $=1 / 19, \mathrm{p}<.05 ;$ goal, $\mathrm{F}$ $=4.72, \mathrm{df}=1 / 19, \mathrm{p}<.05)$. No other significant effects were found.

The significant interactions were further investigated by the use of the Newman-Keuls procedure. Results of these analyses indicated that in the goal measure Group LS-R approached the goal significantly $(p<.01)$ faster than Group SS-R. In the run measure, Groups LS-R and SS-A were both found to be running significantly $(p<.01)$ faster than Group SS-R. In the start measure, Group LS-R started significantly $(p<.01)$ faster than all other groups. Also, Group SS-A started significantly faster than Group SS-R $(p<.01)$ and Group LS-A ( $\mathrm{p}<.05)$.

As can be seen from Fig. 1 and the statistical results mentioned above, the data of the present study are supportive, at least in the case of the normal Ss, of the traditional assumption that the receipt of larger reward magnitudes results in superior performance. Group LS-R showed superior performance, relative to Group SS-R, in all three measures taken. Obviously, as these differences were quite pronounced after 50 trials, these data conflict with the data reported by McCain $(1969,1970,1971)$. In looking for differences between the present study and those of McCain which would help to reconcile the discrepant data, such factors as possible satiation, type of measure(s) reported, and the number of trials administered per day stand out as possibilities. As to which one(s) is ultimately responsible, only further research can ascertain.
Although of a preliminary nature, the results of this study would also caution against the widespread use of anosmic Ss as an odor-control technique until the full behavioral effects of anosmia have been determined. The data reported here would suggest that anosmia, in addition to eliminating reward magnitude effects, may also have the effect of generally reducing performance level. This depression in performance appeared quite strongly in the start measure, where the performance of both groups of anosmic Ss was significantly below that of Group LS-R. Similar, although nonsignificant, trends were noted in the run and goal (see Fig. 1) measures. If one looks at just the start-measure results, there might be a temptation to speculate that large reward was somewhat aversive to the anosmic Ss (i.e., Group LS-A started significantly more slowly than Group SS-A). Similar trends were again noted in the other measures. A larger scale investigation is currently in progress to delineate more fully the behavioral effects of anosmia on runway behavior.

\section{REFERENCES}

Cheal, M. L., \& Sprott, R. L. Social olfaction: A review of the role of olfaction in a variety of animal behaviors. Psychological Reports, 1971, 29, 195-243. (Monogr. Suppl. 1-V29)

Daly, H. B. Learning to escape cues paired with reward reductions following single- or multiple-pellet rewards. Psychonomic Science, 1972, 26, 49-52.

Davis, S. F. Heterogeneous squad composition, odor cues, and the partial reinforcement effect. Perceptual \& Motor Skills, $1973,36,1163-1169$.

McCain, G. Different levels of performance with equivalent weights of reward. Psychonomic Science, 1969, 14, 2-3.

McCain, G. Reward magnitude and instrumental responses: Consistent and partial reward. Psychonomic Science, 1970, 19, 139-141.

McCain, G., Dyleski, K., \& McElvain, G. Reward magnitude and instrumental responses: Consistent reward. Psychonomic Monograph Supplements, 1971, 3(16, Whole No. 48).

Pubols, B. H. Incentive magnitude, learning and performance in animals. Psychological Bulletin, 1960, 57, 89-115.

Traupmann, K. L., \& Wong, P. T. P. Reward magnitude and instrumental responses: A comment. Psychonomic Science, 1971, 23, 13-14.

(Received for publication August 22, 1973.) 